\title{
Ring Artifact
}

National Cancer Institute

\section{Source}

National Cancer Institute. Ring Artifact. NCI Thesaurus. Code C87018.

An artifact that is due to errors in an individual detector calibration. 